The Brock Review Volume 12 No. 1 (2011)

(C) Brock University

\title{
Interview with Siew Te Wong
}

John Sorenson

Siew Te Wong, M.Sc. is CEO and Founder of Bornean Sun Bear Conservation Centre email:wongsiew@hotmail.com

John Sorenson: Most readers of this journal are probably unfamiliar with sun bears. Can you give us an introduction to these animals, telling us briefly about their characteristics, habitat and behaviour?

Siew Te Wong: Sun bears are the least known bears in the world. I am not surprised that readers are unfamiliar with them.

Sun bears are the smallest bear of all the eight living bear species. Two subspecies are recognized: the mainland subspecies (Helarctos malayanus malayanus) which is larger in body size, and the smaller Bornean subspecies (H. m. euryspilus). The adult male Bornean sun bear typically weighs $45 \mathrm{~kg}$ but can weigh up to $65 \mathrm{~kg}$ in captivity. Sun bear have a stocky build with short jet-black fur and a unique chest patch.

Sun bears are found only in the tropical forest of Southeast Asia. Two habitat types exist in this region: the seasonal tropical forest in Asia Mainland with distinct rainy and dry seasons and a predictable annual fruiting cycle; and a seasonal tropical rainforest in Peninsula Malaysia, Sumatra and Borneo with high rainfall all year long and unpredictable supra-annual fruiting cycles.

Sun bears are solitary animals. They are arboreal, spending much of their time high on top of the forest canopy resting, and feeding on fruits. They sometimes look more like primates than bears because of their agility and arboreal behavior. They are diurnal in forests where human activities are low, nocturnal otherwise.

JS: What about the bears as individuals? What is it like to interact with them? There's been a lot of interesting work done recently by people like Marc Bekoff, Jonathan Balcombe, Jeffrey Masson and others about the emotions and personalities of animals and their social interactions. Can you tell us something about these aspects of the bears you have encountered and observed?

STW: Having had the chance to work with a group of sun bears in captivity for some time, it is not difficult to find out that the sun bears are just like our pet dogs and cats, each of them has their individual personalities and characters that are different from the others. They have emotions, feelings, and moods. They have times when they are happy, sad, or in a bad mood. They have times when they like to be playful with other bears and times when they want to be left alone. There are times when they show fear, nervousness, and anger. Like humans and other animals that humans are more familiar with, say, dogs for example, their feelings and emotions can be read from their body 
language, their facial expression, the noise that they make, etc. It is not difficult to "read" their language or what they are trying to express from their body languages and signs after one spends some time to observe these behavior.

I have interacted with rescued sun bear cubs below $20 \mathrm{~kg}$. I tend not to interact with larger bears because they can be rough and simple play can end up damaging. Like all youngsters, bear cubs are very playful and naughty for good reasons. Interacting with them is like interacting with pet dogs, where they constantly initiate the play and are always full of endless energy. Again, different animals have different personalities, some are more playful, some are more wary, and some are shy.

I will include a video link. This was taken when Om and Ah Chong were integrated for the first time. There were many facial expressions, body language, signs, etc. and the process was surprisingly quiet. Real bear fights, in contrast, produce loud noise.

http://www.youtube.com/watch?v=7bQ3m-Hr59o

JS: Why did you establish the Sun Bear Conservation Centre and what is its purpose?

STW: Ever since I started my research work on sun bears in the late 90's, I noticed that sun bears are very little known across the world. Even in the countries where sun bears are found, such as Malaysia, the general public usually does not know anything about them. People who know about sun bears only know what they look like from local zoos or seeing bears kept as pets in small cages. Among the Chinese, knowledge about sun bears is restricted on how to eat them, especially their paws as a delicacy and bear gallbladder is highly sought-after as traditional Asian medicine although very few have actually had the experience of consuming bear parts. There are also many sun bears being kept as pets in very bad conditions.

To make the situation worse, there is almost no interest from the authorities, conservation NGOs or whatever, to engage in any activities to conserve and to save the species. As a biologist who was trained in the Western world, I saw these phenomena as big problems in efforts to conserve the species. Therefore, with the help of many people, I established the Bornean Sun Bear Conservation Centre to promote sun bear conservation by creating the capacity to rescue caged sun bears as the first step, providing an improved living environment for these animals as the second steps, and attempting to rehabilitate those individuals who still have the chance to live in the wild as the third step. At the same time, the centre will serve as a strong base to educate the public about the plight of the sun bears, to raise conservation awareness about this species, and to conduct more research on this species.

JS: Why do the bears need protection? What are the main threats to them?

STW: In a world where the human population is increasing at an exponential rate and rules this world, other species that once shared the Earth with human beings are quickly outcompeted. Without specific protection from human laws, these species, sun bears included, will be driven to extinction. The threats to sun bears are habitat loss, poaching for their body parts, and keeping bears as pets. Among these threats, habitat loss is by far the biggest threat to the survival of sun bears in Southeast Asia. This is why sun bears need protection. 
JS: There is some awareness of the impact of palm oil production on endangered animals such as orangutans; can you describe the impact of this industry on the bears? What other animals are affected? How much of the bears' habitat remains in Malaysia?

STW: The impact of palm oil production on sun bears is similar to the situation of orangutans. Both sun bears and orangutans are forest dependent species, their survival directly reflects the amount of forest available to them. The habitat of sun bears and orangutans, the lowland tropical rainforest in Sumatra and Borneo, is being cleared and converted into oil palm plantation to produce palm oil. Thus, the oil palm industry directly reduces the habitat of sun bears. In areas where oil palm plantations are adjacent to forests where bears still exist, these plantations act like an ecological sink where bears are being poached when they wonder into the plantation to look for food, feeding on the palm seeds. Oil palm production affects all forest dependent wildlife and wild plant species in Malaysia and Indonesia. These wildlife species range from tiny invertebrates, all the way to large mammals such as sun bears, tigers, Bornean clouded leopards, Sumatran rhinos, Bornean pygmy elephants, etc.

In Peninsular Malaysia, approximately 45\% (59,000 km2) of the total land area of the 131,623 km2 remains as various type of forest covers; in Sarawak, $67 \%(83,380 \mathrm{~km} 2)$ of the total land area of $124,450 \mathrm{~km} 2$ remains as various type of forest covers; and in Sabah, 60\% (43,500 km2) of the total land area of $72,500 \mathrm{~km} 2$ remains as various type of forest cover. In theory, these remaining forest covers are potential sun bear habitat. However, in reality, many of these remaining forests are highly fragmented and degraded, some are heavily poached, and sun bear populations are locally extinct and are not considered suitable as sun bear habitat. I identified 8 Sun Bear Conservation Units (SBCUs) in Malaysia. These SBCUs are large totally protected forested areas where sun bears populations are believed to be healthy and safe from perturbation. In Peninsular Malaysia, 4 SBCUs add up to a total of 10,600 km2; In Sabah and Sarawak, the other 4 SBCUs add up to a total of 14,500 $\mathrm{km} 2$. These are pretty much the secured sun bears habitat in the future.

JS: Could you discuss the situation of the sun bears in the context of the international wildlife trade generally? What is driving this trade?

STW: Like other bear species, sun bear body parts are highly sought-after commodities both locally and internationally. Bear gallbladder, canines, claws, and paws, are among the valuable body parts in addition to bear meat and all are being traded illegally across borders. Sun bears are listed as Appendix I species in the Conventional on International Trade in Endangered Species (CITES), an international wildlife law that prohibited the trading of its body parts and the animal itself between countries. However, the lack of law enforcement personnel on the ground, the lack of interest to enforce wildlife law by the authorities, the high profit made from the trade and high prices on the black market are important driving forces behind the international wildlife trade. In addition, the opening of the China market and the ever-increasing buying power in China is another important factor that drives the international wildlife trade, including bear parts.

JS: Who is involved in this trade in Malaysia? Is the wildlife trade important for local communities in Malaysia? Who profits from the trade?

STW: The trade of bear parts in Peninsular Malaysia involves a wide range of people, including the local aborigines (also known as "Orang asli") hunters, foreign poachers (mostly skillful Thai poachers who also collect gaharu [resinous wood] in Malaysian forests), middleman traders (mostly Chinese), 
restaurant operators, individual buyers and probably corrupted law enforcement personal. In Sarawak, the hunters are local Iban and Dayak people who hunt bears and sell body parts, mostly to Chinese middleman in town. These bear parts are either being traded locally or internationally by foreign buyers from Korea, Japan, and mainland China. Sometimes Indonesian traders bring bear parts, especially gallbladders, bear claws and canines, that originated in Indonesia, and sell these items in local night markets.

No study has been conducted on whether this trade is important to local communities. However, any trading and selling of the bear parts will for sure increase earnings of the individual local hunters. The business profits everyone who is involved in the trade, especially the middlemen.

JS: What kind of response are you getting from local communities to your conservation efforts? Are your education campaigns having any effect in changing attitudes?

STW: BSBCC has been established for more than two years by now. However, our work has been concentrated on fundraising to build the centre and taking care of the rescued sun bears over the first two years. We have not yet started our education campaign, which is scheduled to begin sometime in mid 2011 after we have completed the visitor facility and the gallery. Thus, we have not yet had proper responses from local communities to our conservation efforts or seen any change in attitudes.

JS: How is the Malaysian government addressing these issues?

STW: There are three government authorities addressing wildlife (bear) issues in Malaysia. Department of Wildlife and National Park (DWNP) is the wildlife authority in Peninsular Malaysia, Forest Department Sawarak in Sarawak and Sabah Wildlife Department in Sabah. In general, these government agencies take neutral steps in addressing these issues by enforcing wildlife laws at certain degrees. In general, sun bears are a low priority species and there is no active program to conserve sun bears except in Sabah. In Sabah, because of the establishment of BSBCC, SWD actively confiscated illegal keeping of pet sun bears. We also received lots of supports from SWD and Sabah Forestry Department and partner with these government agencies to set up BSBCC.

JS: What is the role of ecotourism in protecting the bears and other wildlife in Malaysia?

STW: Ecotourism could play a potential role in protecting the bears and other wildlife in Malaysia, by creating an incentive to protect wildlife habitat and wildlife themselves besides generating revenue for the country. This ecotourism industry is important to maintain positive images to attract even more visitors, thus generate more revenues, to the country. However, the proportion of ecotourism compared to general tourism is still small in Malaysia. For example, in 2008 approximately 22 million foreign tourists visited Malaysia. In the same year, about 1 million foreign and local visitors combined have visited the ecotourism destinations in Peninsular Malaysia, and about 700,000 foreign tourists visited Sabah where tourism is mostly ecotourism based.

JS: How can people outside Malaysia help your efforts?

STW: Like all conservation programs in the world, the amount of conservation works we can do to help saving species depends on the amount of funding we can generate. My efforts to help save sun bears in Malaysia are not an exception. 
First, we had to raise sufficient funds so that we could set up the centre, run the conservation programs, take care of the rescued bears, etc. We need funding to do all these. The most direct way for people outside Malaysia to help our efforts is donating fund or help us raise funds. They can make the donation online at http://www.leapspiral.org/content/support_leap.php or write to me atwongsiew@hotmail.com. We also have a Facebook cause set up where people can join our cause and make donation at http://www.causes.com/causes/95651.

Unlike tiger, panda, rhinos who are well-known, the sun bear is the least known bear in the world and one of the neglected large mammals in Southeast Asia. The lack of knowledge about the species and their plight among the public is a big obstacle for the conservation efforts to save sun bears. Everyone can help us to raise awareness of the sun bears simply by spreading the word about our cause and the sun bears. The Internet has become an important tool to communicate with friends across the world. Joining our Facebook cause (http://www.causes.com/causes/95651) and repost our blogs (http://sunbears.wildlifedirect.org/) for example, could help us get the message out for sure.

The last thing about how other people can help us is what I always telling people on how they can help us: "do what you do best to help us!" If you are a writer, you can help us write about sun bears and our work; If you are a film maker, help us produce a film about the sun bears; if you are a scholar, help us conduct studies on sun bears, etc. In short, do what you do best! 